ANNALS OF “DUNAREA DE JOS” UNIVERSITY OF GALATI

MATHEMATICS, PHYSICS, THEORETICAL MECHANICS

FASCICLE II, YEAR XI (XLII) 2019, No. 2

DOI: https://doi.org/10.35219/ann-ugal-math-phys-mec.2019.2.07

\title{
INFLUENCE OF SUBSTRATE TEMPERATURE ON THE STRUCTURAL AND OPTICAL PROPERTIES OF ZnSe THIN FILMS
}

\author{
Nicolae Tigau*, Simona Condurache-Bota, Emilian Danila \\ Faculty of Sciences and Environment, Dunarea de Jos University of Galati, 111 Domneasca Street, 800201 \\ Galati, Romania, *e-mail: ntigau@ugal.ro
}

\begin{abstract}
$\mathrm{ZnSe}$ thin films were deposited onto glass substrates by vacuum thermal evaporation technique. The substrate temperature was varied from $300 \mathrm{~K}$ to $473 \mathrm{~K}$. The films structure was studied by means of X-ray diffraction technique (XRD). The film crystallites present a preferential orientation with the (111) planes parallel to the substrate surface. The surface morphology was investigated by vertical scanning interferometry (VSI). The surface roughness parameters of thin films were calculated. The optical properties of $\mathrm{ZnSe}$ thin films were investigated using spectrophotometric measurements of transmittance and reflectance in the 275-1100 nm wavelength range.
\end{abstract}

Keywords: ZnSe thin films, XRD technique, surface morphology, roughness parameters, optical properties

\section{INTRODUCTION}

$\mathrm{ZnSe}$ is a wide band gap $\mathrm{A}^{\mathrm{II}}-\mathrm{B}^{\mathrm{VI}}$ semiconductor and it belongs to the class of chalcogenides [1]. This semiconductor has attracted considerable attention for its wide range of applications in various optoelectronic devices [2]. At room temperature, $\mathrm{ZnSe}$ has electron affinity of $4.09 \mathrm{eV}$ and electron mobility of about $5.30 \times 10^{2} \mathrm{~cm}^{2} \mathrm{~V}^{-1} \mathrm{~s}^{-1}$ and optical band gap of about $2.7 \mathrm{eV}$ [3]. Due to their unique electrical and optical properties, such as low resistivity, high optical transmission and high refractive index in the visible and infrared spectral region, ZnSe thin films have many applications in optoelectronic devices, laser diodes and solar cells [4-7].

ZnSe thin films have been deposited by various methods, such as thermal evaporation under vacuum, electro-deposition, molecular beam epitaxy, atomic layer epitaxy, spray pyrolysis and chemical bath-deposition [8-14]. In this present paper we report the effect of substrate temperature on the morpho-structural and optical properties of $\mathrm{ZnSe}$ thin films obtained by thermal evaporation under vacuum.

\section{EXPERIMENTAL}

ZnSe thin films were deposited onto glass substrates by thermal evaporation of polycrystalline powder of the compound ( $99.99 \%$ purity) in a residual air pressure of $5 \times 10^{-5}$ torr. The substrate 
temperature, $T_{\mathrm{S}}$, was kept constant during film growth at 300 and $473 \mathrm{~K}$, respectively. The deposition rate was kept constant at about $3 \mathrm{~nm} / \mathrm{s}$ in both cases.

The thickness of the films was determined by Fizeau's equal thickness interference fringes method, by using an interferential microscope MII 4 [15]. The value of the thickness, d, obtained for all investigated samples was about $0.60 \mu \mathrm{m}$. A DRON-3 diffractometer with a Co-Ka line $(\lambda=1.7927 \AA)$ was used to get the X-ray diffraction spectra of the ZnSe thin films. The surface morphology of the ZnSe thin films was investigated by vertical scanning interferometry (VSI) using a coherent scanning interferometer type Veeco. The surface parameters associated with the roughness of the films, such as the average roughness, $R_{a}$, root mean square roughness, $R_{q}$, average maximum height of the profile, $R_{z}$, and maximum height of the profile, $R_{t}$, were calculated from the surface profile of the films. The optical transmission and reflection spectra were recorded at normal incidence, in the spectral range $275-1100$ $\mathrm{nm}$ by using a Perkin Elmer Lambda 35 UV-VIS-NIR double-beam spectrophotometer operated at room temperature. The optical constants of the $\mathrm{ZnSe}$ thin films, such as the refractive index, $n$, the extinction coefficient, $k$, and the absorption coefficient, $\alpha$, were calculated from the optical transmission and reflection spectra. The optical band gap, $E_{g}$, of the investigated $\mathrm{ZnSe}$ thin films was determined from the sharply falling transmission region.

\section{RESULTS AND DISCUSSION}

The X-ray diffraction (XRD) patterns of the ZnSe thin films deposited at $300 \mathrm{~K}$ and $473 \mathrm{~K}$ substrate temperatures are shown in Fig. 1. It can be noticed that for the studied temperatures, both films are polycrystalline in nature, having a cubic zinc blende-type of structure, with a strong preferential orientation along the (111) planes parallel to the substrate. The calculated lattice parameter, $a$, of the cubic structure of the films was found to be around $5.68 \AA$ which is in good agreement with those reported in the literature $[9,14,16]$. Fig. 1 also proves that the intensity of the (111) reflection increases with increasing substrate temperature. The grain size, $D$, of the films was calculated from the Debye-Scherrer formula [17]:

$$
\mathrm{D}=\frac{0.94 \lambda}{\beta \cos \theta}
$$

where $\lambda=1.7927 \AA$ is the wavelength of the X-ray radiation, $\beta$ is the full-width at half-maximum intensity corresponding to the $2 \theta=31.6^{\circ}$ Bragg diffraction angle, expressed in radians.

It was found that the grain size of the $\mathrm{ZnSe}$ thin films increases from about $23.6 \mathrm{~nm}$ to $36.5 \mathrm{~nm}$ when the substrate temperature increased from $300 \mathrm{~K}$ to $473 \mathrm{~K}$.

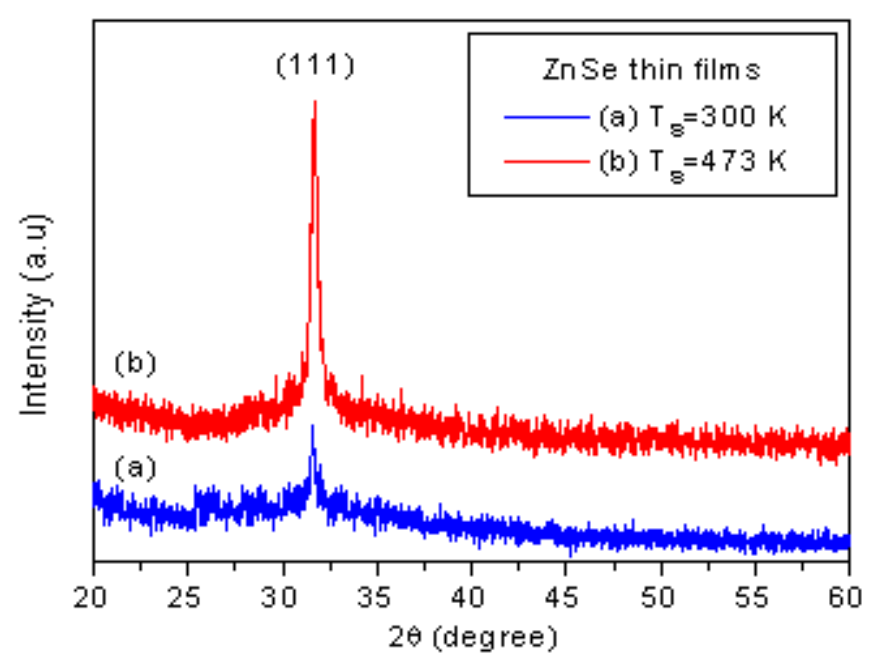

Fig. 1. XRD patterns of the ZnSe thin films under study 
The VSI images of the top surface of the ZnSe thin films deposited at $300 \mathrm{~K}$ and $473 \mathrm{~K}$ substrate temperatures of are shown in Figs. 2(a) and (b), respectively.

The surface parameters associated with the roughness of the films, such as the average roughness, $R_{a}$, root mean square roughness, $R_{q}$, average maximum height of the profile, $R_{z}$, and maximum height of the profile, $R_{t}$, were calculated from the surface profile of thin films (Fig. 3). The values of these parameters are presented in Fig. 2. As it can be easily seen from Fig. 2, all roughness parameters decrease with increasing substrate temperature.

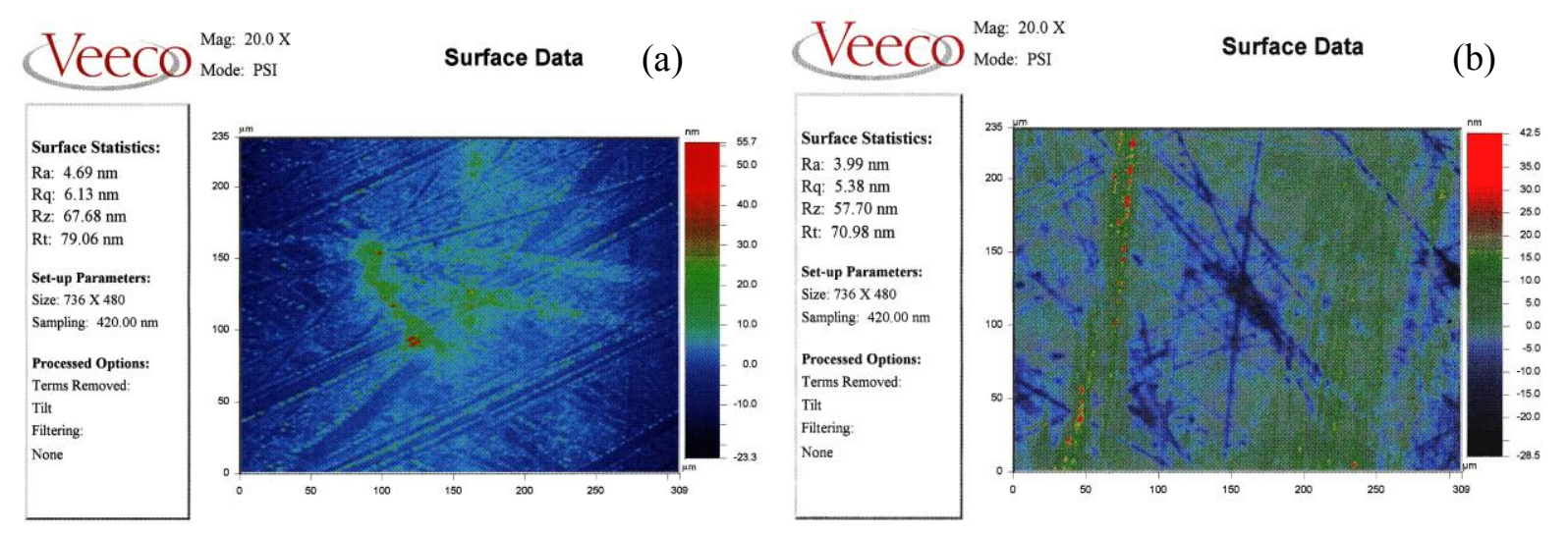

Fig. 2. VSI images of ZnSe thin films deposited at different substrate temperature: (a) $300 \mathrm{~K}$ and (b) $473 \mathrm{~K}$.

(a)

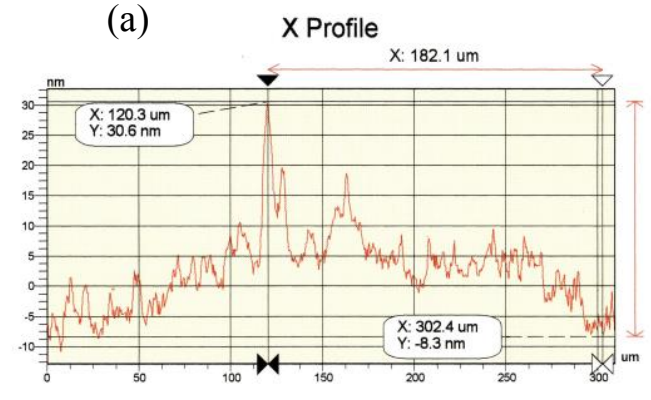

Y Profile

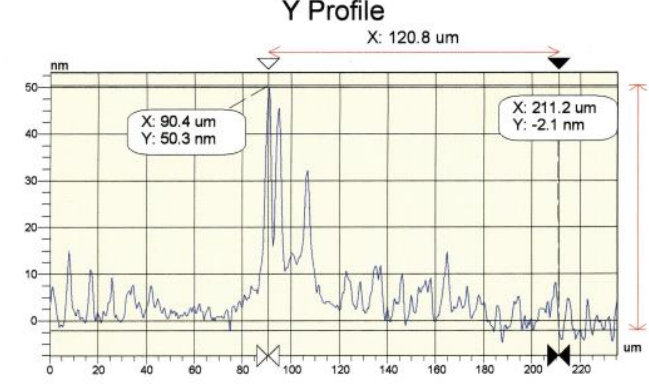

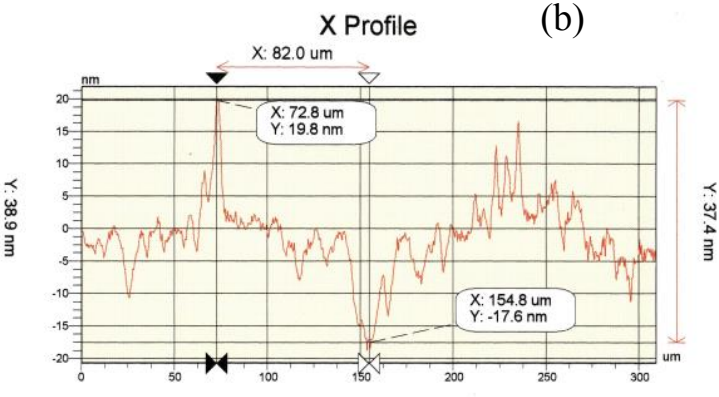

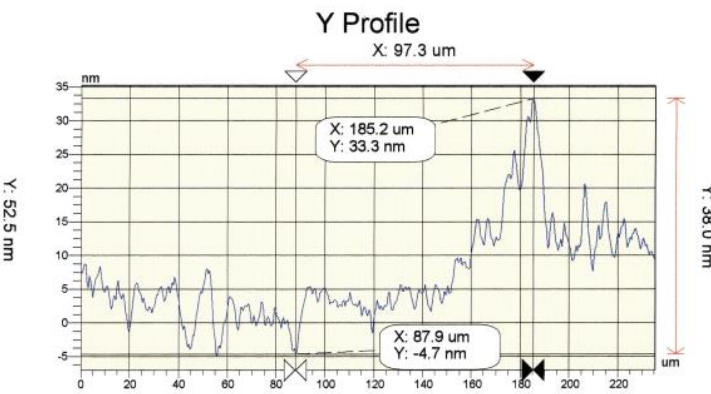

Fig. 3. X and Y profiles of ZnSe thin fims deposited at different substrate temperature: (a) $300 \mathrm{~K}$ and (b) $473 \mathrm{~K}$.

The spectral dependences of the normal incidence transmittance, $\mathrm{T}(\%)$, and reflectance, $\mathrm{R}(\%)$, of the $\mathrm{ZnSe}$ thin films deposited at the two substrate temperatures ( $300 \mathrm{~K}$ and $473 \mathrm{~K}$, respectively) were measured in the 275-1100 nm wavelength range and are shown in Fig. 4. From this figure, it can be seen that at wavelengths above $800 \mathrm{~nm}, \mathrm{~T}+\mathrm{R} \approx 100 \%$, which indicates that the investigated samples exhibit neither scattering, nor absorption. In addition, the transmission spectra of both films exhibit a 
sharp increase in the visible wavelength region. An increase of transmittance in the visible spectral region with increasing substrate temperature is also observed. The optical transmission spectra show that the film deposited at $473 \mathrm{~K}$ is highly transparent having the transmittance above $90 \%$ and has a low reflectance, less than $35 \%$, in the visible region. The high optical transmission of this film indicates a fairly smooth surface, which is consistent with the surface data calculated from the VSI measurements.

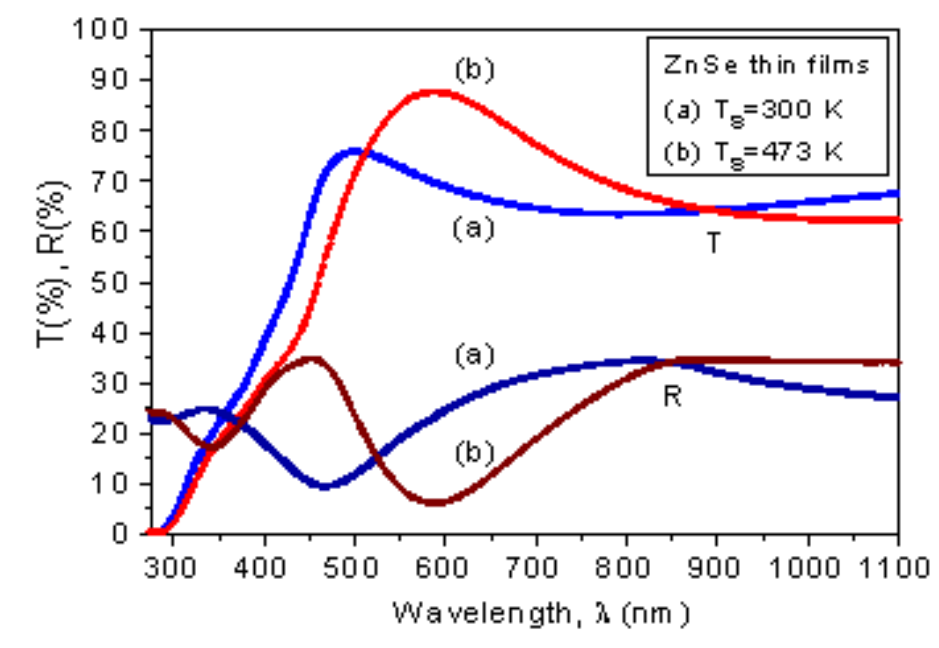

Fig. 4. Spectral dependences of the transmittance, $T$ and reflectance, $R$, of the analyzed ZnSe thin films

\section{CONCLUSIONS}

ZnSe thin films were deposited by vacuum thermal evaporation at two substrate temperatures, namely: $300 \mathrm{~K}$ and $473 \mathrm{~K}$. X-ray diffraction patterns indicate that both investigated films are polycrystalline in nature and present their typical cubic structure, with a (111) preferential orientation. The lattice constant and the grain size of the films were determined from the XRD patterns. It was found that the grain size increases with increasing substrate temperature.

The surface parameters associated with the roughness of the films were determined by vertical scanning interferometry. The VSI studies revealed the smooth surface of the ZnSe thin films. From the VSI images, it was found that the surface roughness of the films decreased as the substrate temperature was increased.

The investigated $\mathrm{ZnSe}$ thin films exhibit high transmittance and low reflectance in the visible wavelength region.

\section{References}

1. Poulopoulos P., Baskoutas S., Karoutsos V., Angelakeris M., Flevaris N. K., Journal of Physics: Conference Series, 10, 259, 2005.

2. Choudhury M.G.M., Islam M.R., Rahman M.M., Hakim M.O., Khan M.K.R., Kao K.J., Lai G.R., Acta Physica Slovaca, 54(4), 417, 2004.

3. Khan T.M., Zakria M., Ahmad M., Shakoor R.I., Journal of Luminescence, 147, 97, 2014.

4. Schulz O., Strassburg M., Rissom T., Pohl U.W., Bimberg D., Klude M., Hommel D., Appl. Phys. Lett., 81, 4916, 2002.

5. Othonos A., Lioudakis E., Tsokkou D., Philipose U., Ruda H. E., J. Alloys Compd., 483, 600, 2009. 
6. Chen L., Lai J.S., Fu X.N., Sun J., Ying Z.F., Wu J.D., Lu H., Xu N., Thin Solid Films, 529, 76, 2013.

7. Xia X., Liu Z., Du G., Li Y., Ma M., Yao K., Journal of Luminescence, 132, 100, 2012.

8. Tigau N., Condurache-Bota S., Rom. Reports Phys., 70(4), 512, (2018).

9. Rusu G.I., Diciu M., Pirghie C., Popa E.M., Appl. Surf. Science, 253, 9500, 2007.

10. Mahalingam T., Kathalingam A., Lee S., Moon S., Kim Y. D., J. New Mat. Electrochem. Systems, 10, 15, 2007.

11. Song J.S., Chang J.H., Oh D.C., Kim J.J., Cho M.W., Makino H., Hanada T., Yao T., J. Cryst. Growth, 249, 128, 2003.

12. Lee C.D., Min S.I., Chang S.K., J. Cryst. Growth, 159, 108, 1996.

13. Bougrine A., El Hichou A., Addou M., Ebothe J., Kachouane A., Troyon M., Mater. Chem. Phys., 80, 438, 2003.

14. Mertin H., Durmus S., Erat S., Ari M., Appl. Surf. Science, 257, 6474, 2011.

15. Chopra K.L., Thin Films Phenomena, McGraw-Hill, New York, 1969.

16. Astraf M., Akhtar S.M.J., Khan A.F., Ali Z., Qayum A., Journal Alloys and Compounds, 509, 2414, 2011.

17. Culity B.D., Elements of X-ray Difraction, Addison-Wesley, London, 1978. 